The European Respiratory Society meeting in Paris in September provided an opportunity for the respiratory journal editors to meet. We discussed key issues such as the working group, led by David Lederer, that has produced a manuscript which will act as an instruction for authors' policy document and details the expectations of all respiratory, sleep and critical journals in terms of the methodology for cohort studies and causal inference (https://www.atsjournals. org/doi/abs/10.1513/AnnalsATS.201808564PS). With all this hard work, it was important that we did some sightseeing...

\section{EIFFEL TOWER}

The Eiffel Tower is a wrought iron lattice tower and named after Gustave Eiffel, its designer. The tower is considered as an engineering masterpiece. Exceptional engineering achievement is not necessarily required when considering improved cookstove design to reduce biomass exposure, but it may have significant clinical impact on adult women and children in low/ middle-income countries. Megha Thakur reports a systematic review and meta-analysis specifically investigating this question (see page 1026). Improved cookstoves had no demonstrable impact on respiratory infections and severe pneumonia in children or on birth weight, miscarriages, stillbirths and infant mortality. However, improved cookstove design was associated with a reduction in COPD in adult women. Perhaps we need Gustave to design a child friendly cookstove.

\section{INSTITUT PASTEUR}

The vaccine against TB was developed by Albert Calmette and Camille Guérin at the Pasteur Institute, and was available for use in human clinical trials from 1921 as BCG. This was a major advance in clinical medicine in terms of TB management, but diagnostic testing for latent TB infection is still under debate. Jason Stout and colleagues report the sensitivity and specificity and latent TB infection prevalence in 10740 high-risk individuals (see page 1062). The data reported reinforcing the guidelines in preferring interferon- $\gamma$ release assays for foreign-born populations and recommending against screening populations at low risk for latent TB infection. We hope Calmette and Guérin would agree.

\section{MONTMARTRE}

The walk up the hill to Montmartre would have probably made the surrounding residents, such as Monet, Renoir, Degas, Toulouse-Lautrec, Picasso and van Gogh, wheeze a little. This may have been the inspiration for the European study from Anna Selby and colleagues who investigated the prevalence estimates and risk factors for early childhood wheeze (see page 1049). The EuroPrevall birth cohort recruited 12 049 infants with the prevalence of wheeze in the second year of life ranging from under $2 \%$ to over $17 \%$ across Europe. Frequent lower respiratory tract infections in the first and second years of life, postnatal maternal smoking, day care attendance and male gender were associated with wheeze. Interestingly, food allergy and breast feeding were not. At least eating the food in Paris will be fine...phew!

\section{ARC DE TRIOMPHE DE L'ÉTOILE}

The Arc de Triomphe honours all those who died for France in the Napoleonic Wars. There was a significant risk to being a soldier in the Napoleonic Wars with a total military death toll of 3.5-7.0 million. Although not focused on mortality, Theodore Lytras and colleagues report on the increased risk of COPD with occupational exposures from the Community Respiratory Health Survey (see page 1008). A total of 3343 participants were included with an incidence of COPD of 1.4 cases/1000 person-years. Participants exposed to biological dust had a higher incidence of COPD compared with those unexposed, as did those exposed to gases, fumes and pesticides. The risk for COPD from occupational exposure today is probably less than the risk of dying as a soldier during the Napoleonic Wars.

\section{PALACE OF VERSAILLES}

The Palace of Versailles was the principal royal residence of France from 1682 under Louis XIV until the start of the French Revolution in 1789 under Louis XVI. The revolution in France led to abolition of the monarchy and we hope the revolution in our understanding of the microbiome may lead to abolition of serious lung disease in cystic fibrosis. Nicole Acosta and colleagues investigated if the microbiome could be used as a biomarker to identify patients who progress to early end-stage lung disease (death or transplantation before the age of 25 years) (see page 1016). Sixteen per cent of patients progressed to early end-stage lung disease and they were more likely to have sputum with low alpha diversity, dominated by specific pathogens including Pseudomonas. Abundant Streptococcus was observed to be protective. Multivariate analysis identified baseline lung function and alpha diversity as independent predictors of death or transplantation under 25 years. Vive la révolution!

\section{JARDIN ANNE FRANK}

This public park was built in honour of Anne Frank and from July this year was one of six public parks in Paris that has banned smoking. This approach may have been prompted by the work of Andreas Neophytou and colleagues who investigated the dose-response relationships between plasma cotinine-determined secondhand smoke exposure and asthma outcomes in children (see page 1041, Editors' choice). From the data of 1172 Latino and African-American children with asthma, the authors showed that exposure to secondhand smoke was associated with higher odds of asthma exacerbations and poorly controlled asthma. Furthermore, there are no safe levels of secondhand smoke exposure and so perhaps the ban should be across all parks, and not just in Paris!

\section{MOULIN ROUGE}

Moulin Rouge is the birthplace of a seductive dance performed by the courtesans, which became known as the Can-Can. As time went on, the Can-Can became a rather energetic dance that required exceptional coordination and balance. Indeed, this was a major consideration for the matched cohort study reported by Ali Hakamy and colleagues (see page 1079). In this study, incidence of falls in patients with COPD was determined. A total of 44400 patients with COPD and 175545 non-COPD subjects were identified with a fall rate per 1000 person-years of 44.9 in the patients with COPD compared with 24.1 in the non-COPD subjects. This equated to a $55 \%$ increase in the likelihood of falls in the patients with COPD and that was on two legs, so patients with COPD should avoid the Can-Can!

(c) Author(s) (or their employer(s)) 2018. No commercial re-use. See rights and permissions. Published by BMJ. 